Kalpa Publications in Civil Engineering
Volume 1, 2017, Pages 388-397
ICRISET2017. International Conference on Re-
search and Innovations in Science, Engineering
\&Technology. Selected papers in Civil Engineering $\quad$ Ka L po

\title{
Modelling and Analysis of Irregular Geometrical Configured RCC Multi- Storey Building Using Shear Wall
}

\author{
Rutvij Kadakia ${ }^{1}$, Dr Vatsal Patel ${ }^{2}$ and Ansu Arya ${ }^{3}$ \\ ${ }^{1}$ P.G. Student, Parul Institute of Technology, Waghodia \\ ${ }^{2}$ Associate Professor, A D Patel Institute of Technology, New V V Nagar \\ ${ }^{3}$ Assistant Professor, Parul Institute of Technology, Waghodia \\ rick143kadakia@gmail.com, vatsalp1976@gmail.com, \\ anshu.arya@paruluniversity.ac.in
}

\begin{abstract}
This study aims to model and study G+14 RCC building with different geometrical configurations and provision of shear wall at different location for zone IV and V. The various parameters like Lateral displacement, Storey drift, Drift ratio, Base Shear are compared for building models developed by using SAP2000 with and without shear wall. The provision of shear wall in multistoried building in zone $V$ improved lateral load carrying capacity and also other parameters are enhanced in comparison with building in zone IV.
\end{abstract}

Keywords—shear wall ; lateral displacement; drift ratio; base shear

\section{Introduction}

Due to tremendous increase in the construction of high rise irregular geometrical residential and commercial buildings, the effect of lateral loads like earthquake load has gain more attention as every designer is facing problem of providing sufficient strength and stability against earthquake. A normal building should possess four main attributes having simple in plan and regular configuration, adequate lateral strength, its stiffness and ductility. Buildings having normal regular geometry in plan and in elevation, suffer much less damage than the irregular configuration. A building shall be considered as an irregular as per IS 1893-2002, if it lacks symmetry and has discontinuity in geometry, mass or load resisting elements. The dynamic loads includes many loads such as wind, waves, traffic, earthquakes, and blasts. Any structure either regular or irregular can be subjected to dynamic loading. Structural symmetry might be a major reason of poor performance of buildings 
under extreme seismic loading; asymmetry contributes significantly to increase lateral deflections, increased member forces and ultimately the buildings tends to collapse.

Shear walls are the vertical elements of the horizontal force resisting system. When shear walls are designed and constructed properly, they will have the sufficient strength and stiffness to resist the horizontal forces. Mainly the Shear walls start at the foundation level and are continuous throughout the building height. The thickness of the shear wall should be as low as $150 \mathrm{~mm}$, or as high as $400 \mathrm{~mm}$ in high rise buildings.

Shear walls are generally provided along both length and width of buildings. Shear walls are like vertically aligned wide beams that carry the earthquake loads down to the foundation.

\section{Literature Review}

(Pardeshi sameer, Gore N. G 2016) ${ }^{[1]}$ analyzed G+15 storied buildings for symmetric and asymmetric building models using ETABS software. The Response spectrum analysis was carried out on T, L, Regular and Plus Shape of regular and irregular RC building frames and ductility based design using IS 13920 corresponding to response spectrum analysis was done. The result showed that the T-shape building had large displacement and building with severe irregularity showed maximum displacement and storey drift. It was found from results obtained from RSA that mass irregular building frames experiencing larger base shear than similar regular building frames and stiffness irregular building experiencing lesser base shear and has larger inter storey drifts. The storey drift for all the stories were found to be within the permissible limits.

(Mohan \& Prabha, 2011) ${ }^{[2]}$ modeled six and eleven storey buildings using software SAP 2000v12 for earthquake zone V in India on six different types of shear walls. Six different types of shear walls such as L, U, Square, Double U, I and T with its different variation in shape. The study is to be considered for resisting the lateral forces and their effectiveness. The results showed that the percentage variation of the $\mathrm{U}$ and $\mathrm{T}$ shape frame model among the two methods had higher variation compared to all other models. Equivalent Static Method (ESM) is used effectively for symmetric buildings up to $25 \mathrm{~m}$ height and for building greater than $25 \mathrm{~m}$ height or unsymmetrical buildings Response Spectrum Method (RSM) should be used. Square shaped Shear Walls were more effective and $\mathrm{L}$ shaped Shear Walls were less effective. (Harne, 2014) ${ }^{[3]}$ had conducted the study to determine the strength of reinforced concrete shear wall of a high-rise irregular building by changing location of shear wall. 3 different cases of positioning of shear wall for a 6-storey building was analyzed by STAAD PRO. Different cross sections of RC shear wall such as Box type, L type and cross type shear wall and their location such as along periphery, corner and middle positions. The lateral deflection of column in which shear wall provided along periphery was reduced compared to other models. The effect of S.F. and B.M. due to earthquake at ground storey was more in comparison to top storey and middle level. Besides other load combinations, the combination of 1.5DL+1.5EQX was found to be the most critical combination for all the models and the top deflection has been reduced after providing type II shear wall in Xdirection as well as in Y-direction. L-type shear wall was found more efficient than all other types Shear walls.

(Damam, 2015) ${ }^{[4]}$ determined the solution for shear wall location in multi-storey building with help of four different models. First model was of bare frame type and other are of frames having different locations on shear walls. A structure was of $(\mathrm{G}+10)$ storey building and lateral displacement evaluation being done and analysis was done by F.E.M using SAP2000. Model I-the bare frame type, Model II-the coupled type wall with openings and core type shear walls provided at the lift wells of frame structure, Model III-the rectangle type shear walls at four corners of framed structure and the Model 4 and the last model was core type shear walls provided at lift and rectangular type shear wall 
frame structure. Core type shear wall provided at the corner reduced shear force and bending moments of the buildings.

(Ch \& Ramancharla, 2014) ${ }^{[5]}$ modeled an irregular high-rise $\mathrm{G}+15$ building with shear wall and without shear wall using ETABS as a space frame with a grid of columns along the vertical direction, inter-connected with beam members in the direction orthogonal to each floor level to understand the lateral loads, story drifts and torsion effects. Dynamic linear and non-linear analysis using (RSM) and (THM) had performed and lateral load analysis had been done for structure without shear wall and structure with shear wall. It has been experienced that lateral forces were reduced when the shear walls were added at the appropriate locations of frames having minimum lateral forces. (COM), (COS) and eccentricity of the structure with and without shear walls done and structure with shear wall, centre of stiffness shifts near to center of mass reducing the torsional effect in the structure.

\section{Proposed Methodology}

\subsection{EQUIVALENT STATIC ANALYSIS}

In Equivalent static analysis method it is based on the assumption that the structure responds in its fundamental mode. The response is being read from a design response spectrum giving the natural frequency of the structure. The Equivalent static method works well for low to medium-rise buildings without significant lateral-torsional modes, in which only the first mode in each direction is of significance. The applicability and the reliability of this method has been extended in many building and design codes by applying modification factors accounting for higher buildings with some higher modes, and for lower levels of twisting. Accounting effects during yielding of the structure, many codes applied modification factors reducing in the design forces.

\subsection{RESPONSE SPECTRUM ANALYSIS}

The Response Spectrum Analysis approach depicts the multiple modes of response of a building to be taken into account (in the frequency domain). The response of a structure shall be defined as a combination of many special irregular shapes that in a vibrating string correspond to the harmonics. Computer and software analysis can be used for determination of the modes for a structure. For every single mode, a response should be read from the design spectrum, depending on the modal frequency and the modal mass, and then combined to provide a desired estimate of the total response of the structure. The result obtained from the response spectrum analysis method using the response from a ground motion is typically different from that calculated directly from a linear dynamic analysis using the ground motion, however the phase information is lost in the process of generating the response spectrum. In different cases where structures are too irregular, too tall or of significance to a community in disaster response, the response spectrum approach is no longer available, and more complex and detailed analysis is often required, such as non-linear static analysis or non-linear dynamic analysis.

Different types of Combinations methods are as follows:

- Absolute - peak values are added together

- Square root of the sum of the squares (SRSS)

- Complete Quadratic Combination (CQC)

\subsection{TIME HISTORY ANALYSIS}

Nonlinear dynamic analysis or Time history analysis gives the combination of ground motion records with a detailed structural model, capable of analysing the correct results with relatively low 
uncertainty. In nonlinear dynamic analyses, the structural model subjected to a ground-motion record produces the estimate of component deformations for each and every single and multiple degree of freedom in the model and the modal responses are then combined using schemes such as the squareroot-sum-of-squares and complete quadratic combination method. The limitation of this method is that the assumptions made during the design of structures for checking the suitability fails to give the accurate results compared to method of assigning the lateral forces.

\section{Structural Modelling and Analysis}

The structural analysis and design of $\mathrm{G}+14$ storey reinforced concrete asymmetrical building is done with the help of SAP2000 software. The location of the building is situated in in seismic zones IV and V. All columns in all models are pinned at the base for simplicity. The plan area is $398.83 \mathrm{~m}^{2}$. The floor to floor height is $3 \mathrm{~m}$. Live load on floor is taken as $3 \mathrm{KN} / \mathrm{m}^{2}$ and on roof is $1.5 \mathrm{KN} / \mathrm{m}^{2}$. Floor finish on the floor is $1 \mathrm{kN} / \mathrm{m}^{2}$. Thickness of slab is $125 \mathrm{~mm}$. Shear wall thickness is of $250 \mathrm{~mm}$ on all the beams. The seismic weight is calculated conforming to IS 1893-2002(Part-I). The unit weight of concrete is taken as $24 \mathrm{KN} / \mathrm{m}^{3}$. The grade of concrete for column, beam and slab is considered as M25.The building is special moment resisting frame considered to be situated in seismic zone IV and V having medium soil and intended for residential use.

Two models were prepared on the basis of the plan area shown in Fig.1 and analysis of the models was done through the SAP 2000 software. The Static and Dynamic analysis was done based on the load cases and combinations and the results obtained in form of graphs were obtained for further study.

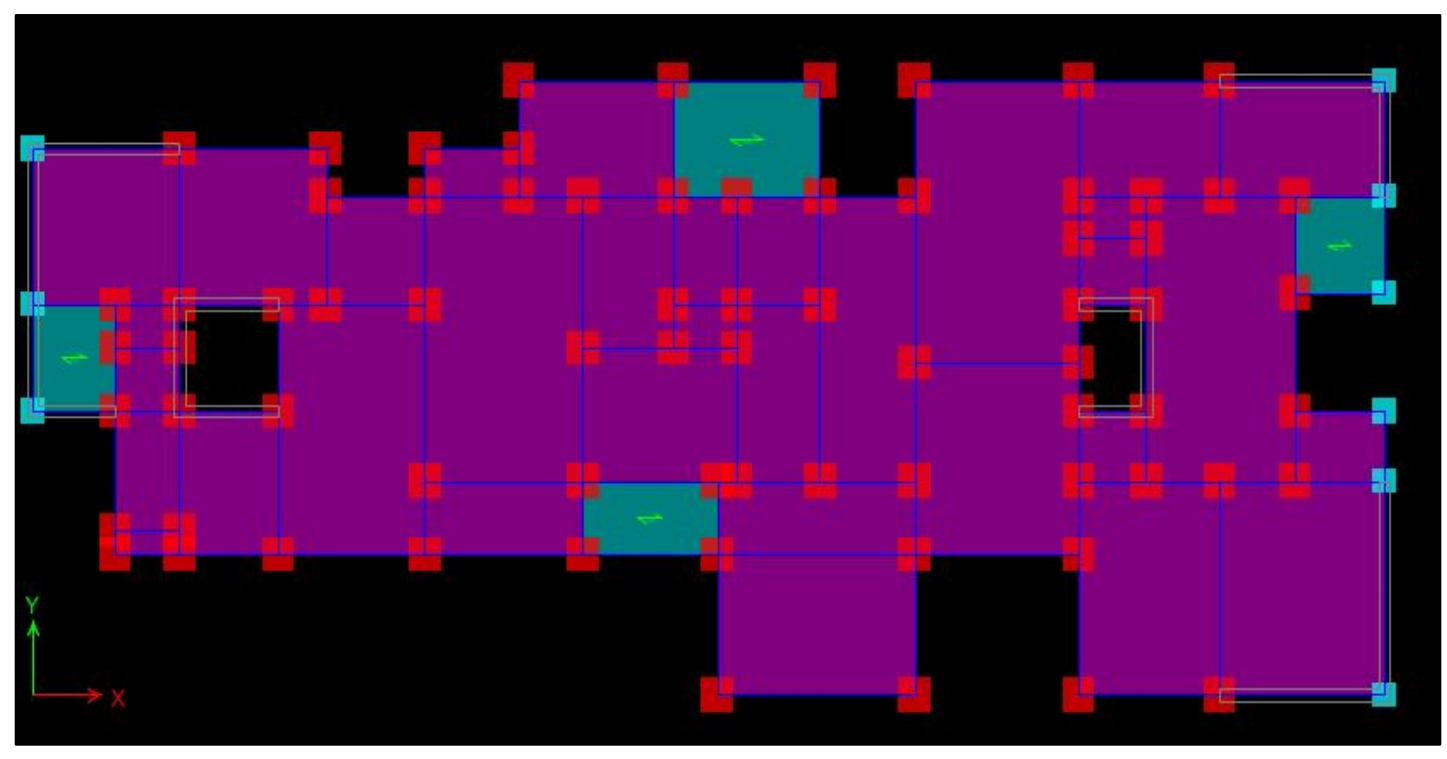

Figure 1: Plan of Building 


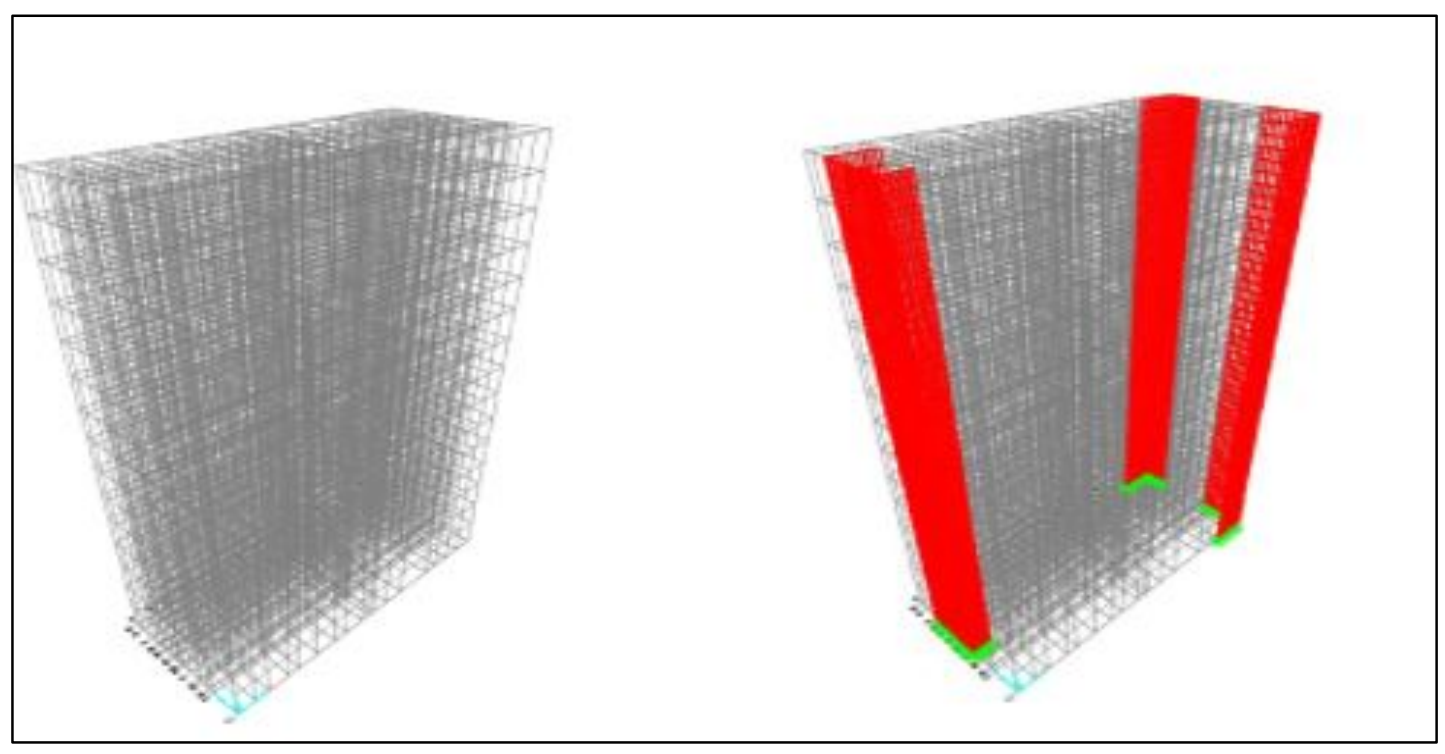

Figure 2: Building model without shear wall and with L-shaped shear wall

\subsection{Loads Assigned}

The Earthquake load is considered as per the IS 1893-2002. The loading was considered keeping in mind the zone factor, Response reduction factor, Importance Factor, Type of soil. Scale Factor $=\mathrm{Z} / 2 * \mathrm{I} / \mathrm{R} * \mathrm{Sa} / \mathrm{g}$

$=0.2354$ for Zone IV

$=0.3531$ forZone $\mathrm{V}$

\section{Results and Discussion}

\subsection{Lateral Displacement}

Analysis of $\mathrm{G}+14$ storied irregular frame model without shear wall and with L-type shear wall models is done using SAP 2000v18.1 software. From the response spectrum analysis results obtained for two model are compared. The results of the displacement in X direction and Y-direction of each floor of different model situated in different earthquake zones are shown in Fig-3.It has been observed that the lateral displacement of the model with the shear wall provided at the corners with respect to model without shear wall is less after comparing the results. 

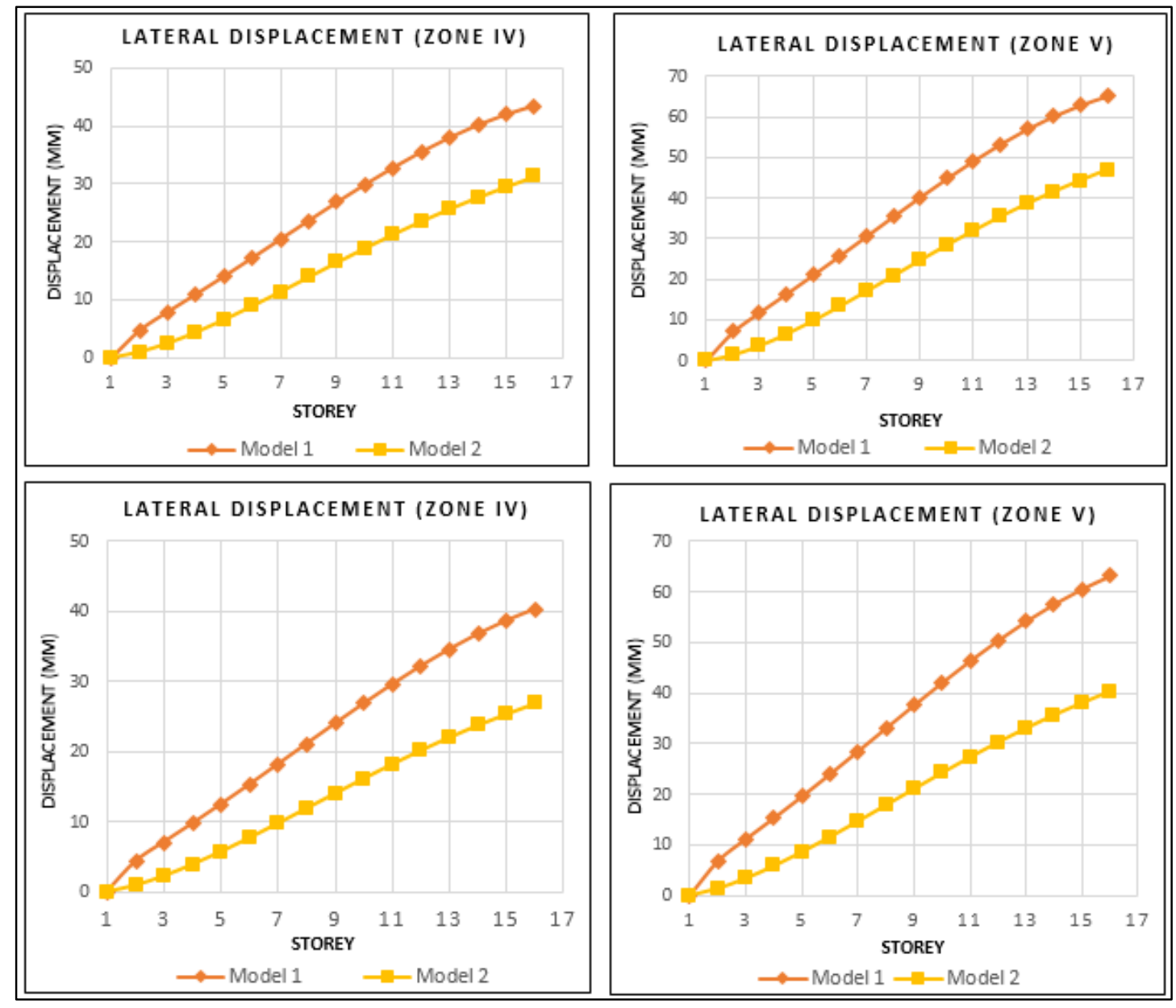

Figure 3: Building with and without shear wall in Zone-IV and Zone-V in $\mathrm{X}$ and $\mathrm{Y}$ direction

The maximum lateral displacement in Zone $\mathrm{V}$ at top floor is $65 \mathrm{~mm}$. The lateral displacement in $\mathrm{Y}$ direction in all zones is less than the lateral displacement in X-direction. The maximum lateral displacement in Zone $\mathrm{V}$ at top floor is $63 \mathrm{~mm}$ which is more than the zone IV. The differences in lateral displacement in both $\mathrm{X}$ and $\mathrm{Y}$ direction is $3 \mathrm{~mm}$.

From Fig.4-Fig.7, it is clear that the difference in lateral displacement along X-direction in model 1 and 2 at top floor in Zone IV is $12.2 \mathrm{~mm}$ and in Zone $\mathrm{V}$ is $18.30 \mathrm{~mm}$. and the percentage reduction in displacement at top floor in model 1 and 2 in Zone IV is 39.04\% and in Zone V is $39.04 \%$ respectively and the difference in lateral displacement along Y-direction in model 1 and 2 at top floor in Zone IV is $13.42 \mathrm{~mm}$ and in Zone $\mathrm{V}$ is $22.77 \mathrm{~mm}$ and the percentage reduction in displacement at top floor in model 1 and 2 in Zone IV is $49.86 \%$ and in Zone V is $56.40 \%$ respectively. 


\subsection{Storey Drift}

Storey drift is the displacement of one level relative to the other level above or below. Storey Drift of Zone IV and V along X direction and along Y direction is shown in Fig.8, Fig.9, Fig.10 and Fig.11.
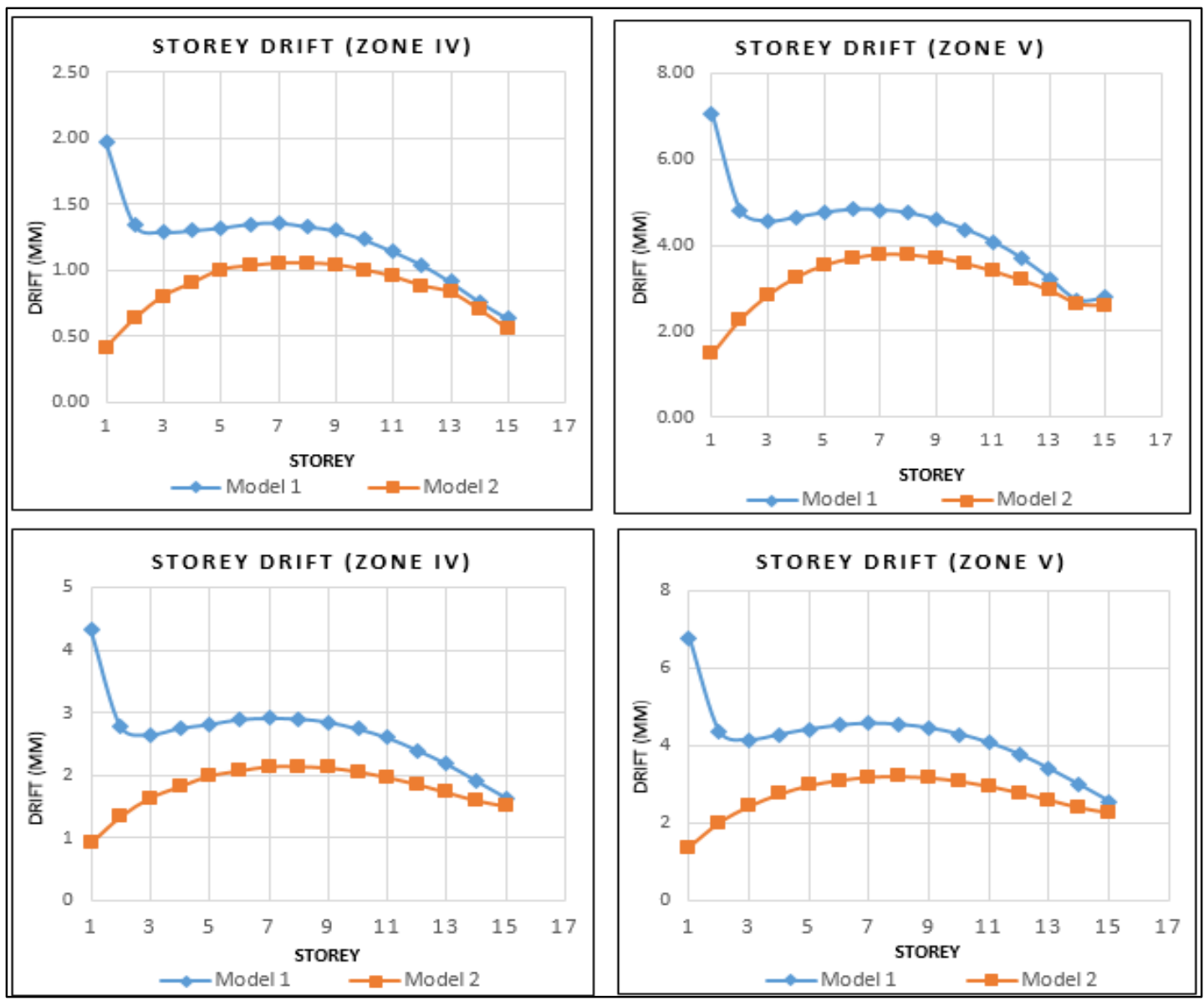

Figure 4: Storey Drift of model with shear wall and without shear wall in most severe zone in in $\mathrm{X}$ and $\mathrm{Y}$ direction

From Fig.4, it is clear that, the difference in Storey drift along X-direction in model 1 and 2 among top floor in Zone IV is $3.73 \mathrm{~mm}$ and in Zone $\mathrm{V}$ is $5.59 \mathrm{~mm}$ and the percentage reduction in drift along $\mathrm{X}$-direction in model 1 and 2 in Zone IV is $79.19 \%$ and in Zone V is $79.06 \%$ respectively. Zone V has the maximum percentage reduction in the storey drift compared to Zone IV in X-direction. The difference in storey drift along Y-direction in model 1 and 2 among all floor in Zone IV is $3.40 \mathrm{~mm}$ and in Zone $\mathrm{V}$ is $5.39 \mathrm{~mm}$ and the percentage reduction in drift at along Y-direction in model 1 and 2 in Zone IV is $78.70 \%$ and in Zone $\mathrm{V}$ is $79.61 \%$. Zone IV has the maximum percentage reduction in the storey drift compared to Zone $\mathrm{V}$ in $\mathrm{X}$ and $\mathrm{Y}$-direction. Results after providing the Shear wall at corners due to which the drift is decreased and at the top floor the point coincide which is known as Inter-Storey drift which is the difference in roof and floor displacement. 


\subsection{Drift Ratio}

Storey drift ratio is the difference between displacements of two stories by height of one story. Storey drift ratio of the zones IV and V along Y direction in the form of graph is shown in Fig 5.

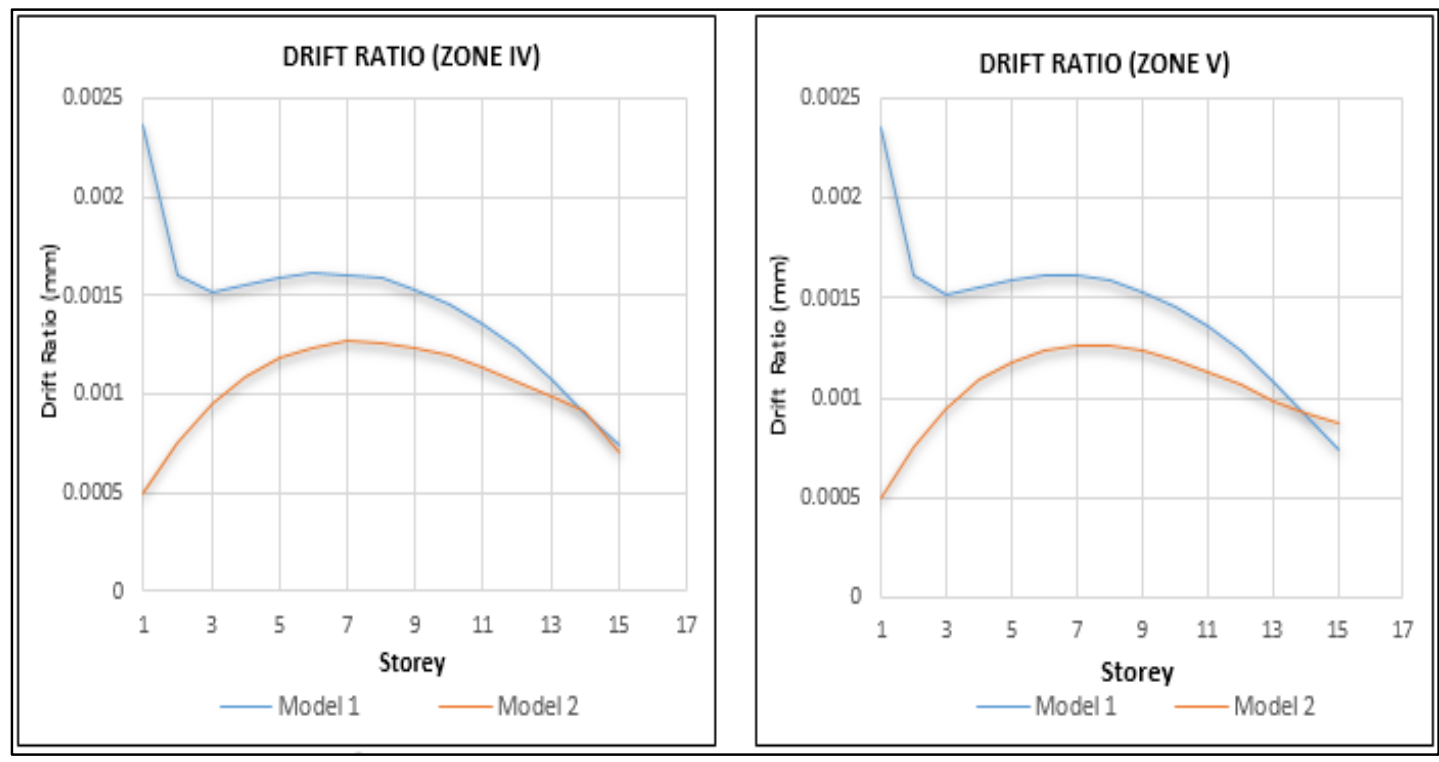

Figure 5: Comparison of drift ratio in Zone $\mathrm{V}$ in $\mathrm{X}$ and $\mathrm{Y}$ direction

The difference in total drift ratio along X-direction in model 1 and 2 among all floor in Zone IV is $0.0075 \mathrm{~mm}$ and in Zone $\mathrm{V}$ is $0.0061 \mathrm{~mm}$ and the average percentage reduction in drift ratio along $\mathrm{X}$ direction in model 1 and 2 in Zone IV is $40.9 \%$ and in Zone V is $39.1 \%$ respectively. Zone IV has the maximum percentage reduction in the drift ratio compared to Zone $\mathrm{V}$ in $\mathrm{X}$-direction.

\subsection{Base Shear}

Base shear is an estimate of the maximum expected lateral force that will occur due to seismic ground motion at the base of a structure. Base shear of the building mainly depends on the value of zone factors. Base shear of the models in zone IV and V are shown in Fig 13 and Fig.14.

There has been change in the base shear in Model-1 and Model-2 because of providing shear wall at the corners there has been slight increase in total base shear compared to building without shear wall. This is due to the seismic weight of the structure and weight of the shear wall. The total percentage increase in Base shear along X-direction in model 2 compared to model 1 in Zone IV is $27.80 \%$ and in Zone $\mathrm{V}$ is $41.71 \%$ respectively. Zone $\mathrm{V}$ has the maximum percentage increase in the base shear compared to Zone IV. The total percentage increase in Base shear along Y-direction in model 2 compared to model 1 in Zone IV is $27.82 \%$ and in Zone $\mathrm{V}$ is $41.71 \%$ respectively. The difference in total base shear in model 1 and model 2 along $\mathrm{Y}$ direction is less compared to base shear along $\mathrm{X}$ direction. 


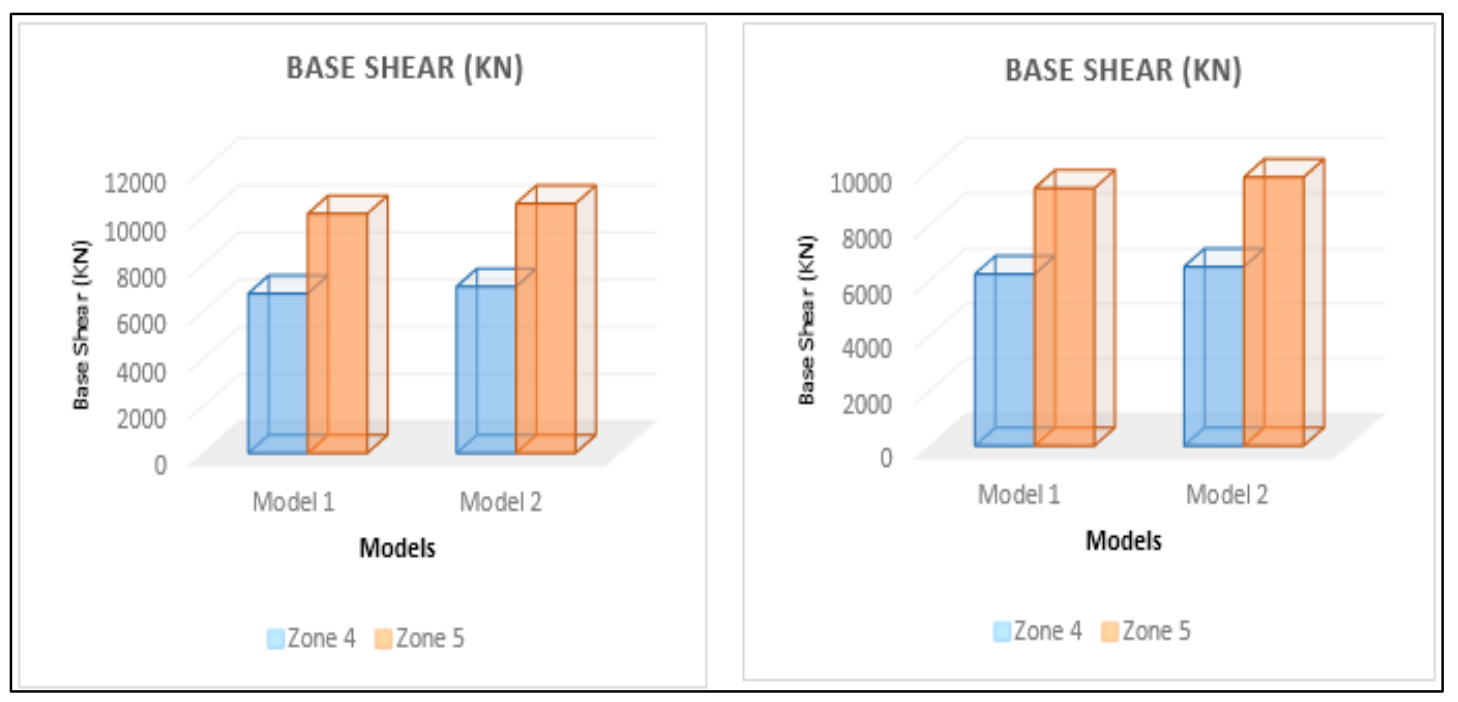

Figure 6: Base Shear in model-I and model-II along X and Y direction

\section{Conclusions}

The following conclusions are derived from the study.

a) Zone $\mathrm{V}$ has the maximum reduction in the lateral displacement in $\mathrm{X}$ and $\mathrm{Y}$ direction in model-II than in model-I compared to Zone IV.

b) The Inter-story drift in Zone IV and V is decreased due to the provision of shear wall in model-II compared to model-I.

c) Zone IV has the maximum percentage reduction in the storey drift along X-direction compared to Zone $\mathrm{V}$.

d) Zone $\mathrm{V}$ has the maximum percentage reduction in the storey drift along Y-direction compared to Zone IV. Zone IV has nearly $50 \%$ reduction.

e) Zone IV has the maximum percentage reduction in the drift ratio along X-direction compared to Zone $\mathrm{V}$. Zone $\mathrm{V}$ has nearly $40 \%$ total reduction.

f) Zone $\mathrm{V}$ has the maximum percentage reduction in the drift ratio along $\mathrm{Y}$-direction compared to Zone IV. Zone IV has nearly $49 \%$ reduction.

g) Zone $\mathrm{V}$ has the maximum percentage increase in the base shear compared to IV.

h) The difference in total base shear in model 1 and model 2 along $Y$ direction is less compared to base shear along X-direction.

\section{References}

1. Ch, R., \& Ramancharla, P. K. (2014). Significance of Shear Wall in Highrise Irregular Buildings, 33(January) " International Journal of Applied Science and Resesarch", 1-4.

2. Damam, V. S. (2015). Comparative Study on Multistoried RCC Structure with and without Shear Wall by using SAP2000 v17. International Research Journal of Engineering and Technology, 2(7), 1261-1266.

3. Harne, V. R. (2014). Comparative Study of Strength of RC Shear Wall at Different Location on Multi-storied Residential Building. International Jpournal of Civivl Engineering 
Resesarch, 5(4), 391-400.

4. Mohan, R., \& Prabha, C. (2011). Dynamic Analysis of RCC Buildings with Shear Wall. International Journal of Earth Sciences and Engineering, 4(6), 659-662. Retrieved from http://ace-klu.in/img/020410346.pdf

5. Pardeshi sameer, P. N. G. G. (2016). Study of seismic analysis and design of multi storey symmetrical and asymmetrical building. International Resesarch Journal of Engineering and Technology, 1893, 732-737.

6. IS: 875 (Part 1) - 1987, “Code of Practice for Design Loads (Other Than Earthquake) for Buildings and Structures - Dead Loads" Bureau of Indian Standards, New Delhi

7. IS: 875 (Part 2) - 1987, "Code of Practice for Design Loads (Other Than Earthquake) for Buildings and Structures - Imposed Loads" Bureau of Indian Standards, New Delhi.

8. ] IS: 875 (Part 3 - 1987, "Code of Practice for Design Loads (Other Than Earthquake) for Buildings and Structures - Wind Loads" Bureau of Indian Standards, New Delhi

9. IS: 1893 (Part 1) - 2002; "Criteria for Earthquake Resistant Design of Structures - general provisions and buildings", Bureau of Indian Standards, New Delhi 